
complejo y controvertido. Las versiones publicadas hasta ahora han sido enfocadas de formas muy diversas y, por lo tanto, nos muestran técnicas de traducción diferentes. El objetivo de este artículo es analizar las distintas traducciones al español que existen de The House on Mango Streety Woman Hollering Creek de Sandra Cisneros y de How the García Girls Lost Their Accents y How Tia Lola Came To Visit Stay de Julia Álvarez, así como estudiar la posible influencia del poder en las distintas versiones.

PALABRAS CLAVE: traducción, literatura chicana, poder, Sandra Cisneros, Julia Álvarez.

\title{
Escritoras híbridas, \\ traducciones dobles y la influencia del poder en el proceso traductor
}

Hybrid Writers, Double Translations and the Influence of Power in the Translation Process

The translation into Spanish of Chicana literature is a complex and controversial subject. The versions published until now have very different approaches and therefore show different translation techniques. The aim of this article is to analyze the diverse Spanish translations of The House on Mango Street and Woman Hollering Creek by Sandra Cisneros and of How the Garcia Girls Lost Their Accents and How Tia Lola Came To Visit Stay by Julia Álvarez. The article will also explore the possible influence of power in these dif-

Maria López Ponz ferent versions.

KEY WORDS: translation, Chicana literature, power, Sandra Cisneros, Julia Álvarez. 


\section{INTRODUCCIÓN}

El objetivo de este artículo es analizar las dife84 rentes versiones en español que existen de varias novelas de Sandra Cisneros y Julia Álvarez; el interés de dicho análisis reside no sólo en la posibilidad de estudiar diferentes enfoques y técnicas de traducción, sino también en examinar la influencia del poder en el proceso traductor y, por lo tanto, en el resultado final. La compleja realidad que describen las novelas chicanas $^{\mathrm{I}}$ escritas por mujeres no siempre ha sabido reflejarse en las traducciones, pero no es mi intención enfocar este análisis de forma prescriptiva, sino mostrar que toda obra literaria (y la traducción, sin duda, lo es) es hija de su tiempo y sus circunstancias, por lo que resulta engañoso juzgar su producción según los estándares de un contexto diferente. Es más fructífero examinar el proceso traductor y el resultado final tratando de entender las condiciones históricas, culturales, económicas, laborales y sociales que lo rodearon, ya que la traducción «does not happen in a vacuum, but in a continuum» (Bassnett y Trivedi, I999: 2). Por lo tanto, un análisis contextualizado nos proporciona claves para saber qué circunstancias propiciaron las decisiones del traductor,

\footnotetext{
Este artículo se enmarca dentro de la actividad del Proyecto de Investigación de Excelencia de la Junta de Castilla y León GR277 «Inmigración y políticas de traducción: nuevos retos de la mediación intercultural en el siglo XXI».

I Aunque originariamente el término chicano estaba ligado a la clase trabajadora de mexicanos que vivían en EE. UU., hoy en día abarca por igual a los inmigrantes nuevos como a las generaciones ya nacidas en este país. Además, debido a la carga política e ideológica que ha adquirido, también se utiliza a menudo para englobar a las personas procedentes de países del centro y sur de América y del Caribe que abogan por una identidad mestiza y que están de acuerdo con las ideas que connota la utilización de este término.
}

qué razones se esconden tras sus aciertos y sus errores.

\section{DISTINTOS ENFOQUES, DISTINTAS TRA- DUCCIONES}

Pilar Godayol, traductora al catalán de varias obras de Sandra Cisneros, afirma que la reescritura de las autoras chicanas puede hacerse desde dos perspectivas: sin tener en cuenta la otredad que pretenden transmitir y, por lo tanto, respetando conceptos como la equivalencia total que han estado presentes en los discursos hegemónicos a lo largo de la historia de la traducción. O desde la hibridación (con)textual que presenta la propia autora, un espacio donde no existen los significados únicos y el traductor es más consciente de sí mismo y de la otredad. $\mathrm{El}$ hecho de pertenecer a un colectivo que no es mexicano, ni estadounidense, ni híbrido, no significa que las traducciones tengan que neutralizar la otredad o representar de forma esencialista la cultura chicana. El traductor asume el riesgo y el compromiso de (re)construir cultural y socialmente a una autora y a su obra desde un contexto diferente; es responsable del ejercicio de poder que supone (re)crear una subjetividad diferente a la suya (1999:36).

Aunque no han tenido una gran difusión en España, son diversas las novelas de autoras chicanas que se han traducido a nuestro idioma, el objetivo de este artículo es examinar en detalle las «dobles traducciones» de Woman Hollering Creek y The House on Mango Street de Sandra Cisneros; y How the Garcia Girls Lost Their Accents y How Tia Lola Came To Visit Stay de Julia Álvarez.

Si nos fijamos en cómo utilizan la lengua las dos autoras que vamos a analizar, Cisneros confronta las culturas norteamericana y mexicana 
mediante un uso muy particular del lenguaje. Utiliza su conocimiento del registro oral del español mexicano y lo plasma en el texto inglés, por lo que a menudo la estructura sintáctica resulta extraña para un lector inglés monolingüe. Aunque la hibridación está presente en todo el texto, es en los diálogos donde se hace más evidente cómo utilizan el lenguaje los habitantes del entre, sus personajes mantienen un tono coloquial en el que se mezclan ambas lenguas y que refleja el habla de los chicanos. Cisneros marca tipográficamente los términos españoles, algunos tienen una carga cultural, es decir, sería difícil encontrar una palabra inglesa que los definiera porque representan objetos o conceptos que no existen en la cultura estadounidense; pero otros se mantienen en español para reflejar que el cambio de código va más allá de unos términos específicos, porque en su caso el bilingüismo es bilanguaging, es un continuo pensar entre lenguas y culturas, un continuo pasar de un lado de la frontera al otro y viceversa. Traducir sus diálogos es, por lo tanto, una tarea delicada en la que cada palabra cobra una significación especial. Observemos como ejemplo la traducción de Caramelo, realizada por Liliana Valenzuela, quien mantiene el cambio de lenguas y además, no adapta el texto al español de España, sino que mantiene el registro propio de los chicanos consiguiendo así que remita a los lectores al mismo contexto que la versión inglesa. Sin embargo, para que este modo de emplear el lenguaje no extrañe al público español, al comienzo del libro se incluye una nota del editor que dice: «La presente edición reproduce la forma en que los habitantes de las comunidades fronterizas sintetizan un lenguaje formado de palabras en inglés y español, el llamado "lenguaje de la frontera"». También se añade una «Nota a la traducción» al final de la obra en la que Valenzuela afirma que la historia era «un intrincado y fino bordado» (2003: 539) y que su versión pretende ser el revés de ese bordado. Cabe señalar que Valenzuela, escritora y traductora procedente de México y afincada en Texas, es un caso particular dentro de nuestro campo, puesto que se ha convertido en una figura casi tan conocida como los autores a los que traduce. Dado que ella misma es chicana, en sus trabajos nunca se pierde el contexto cultural o lingüístico, a menudo más bien ocurre todo lo contrario: sus versiones en español son más «chicanas», están más marcadas lingüística y culturalmente que la propia obra original. Debido a la originalidad y al particular estilo que imprime a sus trabajos, son muchos los autores que solicitan sus servicios, así ha traducido a Sandra Cisneros, pero también a Denise Chávez, Ana Castillo, Rudolfo Anaya o a la otra autora analizada en este artículo. La hibridación en el lenguaje de las novelas de Julia Álvarez, nacida en Nueva York de padres dominicanos, no se evidencia tanto en la cantidad de términos españoles en sus obras, que no son numerosos y siempre están marcados en cursiva, sino en el modo en que los personajes a menudo emplean un inglés sintáctica y semánticamente influenciado por el español: "With patience and calm, even a burro can climb a palm.'This last was one of her many Dominican sayings she had imported into her scrambled English» (Álvarez, I991: I38).

Es posible encontrar numerosas técnicas y estrategias de traducción en las diversas versiones que existen de estas novelas, tanto porque hay múltiples factores que influyen en el trabajo del traductor y en su calidad, desde el conocimiento del contexto original o la ideología de la editorial hasta asuntos más mundanos como los plazos de entrega o el presupuesto económico; como porque los significados de un texto son tan variados como sus lectores y el traductor es, 
ante todo, un lector, por lo que «puede haber tantas traducciones como traductores, cada uno ofreciendo su propia interpretación de una obra» (Valenzuela, 2003: 544).

\section{LAS «DOBLES TRADUCCIONES»}

El propósito de este artículo es centrarnos en un caso curioso que arroja luces y sombras sobre el proceso particularmente complicado de traducir a las autoras chicanas. Si bien es posible que haya más, analizaremos cuatro novelas que tienen dos versiones en nuestro idioma: Woman Hollering Creek y The House on Mango Street de Sandra Cisneros y How the Garcia Girls Lost Their Accents y How Tia Lola Came to Visit Stay de Julia Álvarez. En los tres primeros casos, las primeras traducciones fueron realizadas en España, por traductores españoles y publicadas en la colección Tiempos Modernos de Ediciones B. Las segundas versiones fueron realizadas en América y publicadas por Vintage. En cambio, la última de las novelas presenta una historia ligeramente diferente, ya que ambas traducciones fueron realizadas y publicadas en Estados Unidos por la misma casa editorial, Random House.

Sabiendo que la traducción no es precisamente el campo en el que más dinero se invierte, llama la atención que se realicen dos versiones de una misma obra en un periodo de tiempo relativamente corto. Cabe pensar que se han realizado para dos públicos diferentes y que, por lo tanto, se van a comercializar en lugares distintos, pero la realidad es que las primeras traducciones ya no se editan ni se venden en España y han sido sustituidas por las que se hicieron después. Al margen de estas curiosas circunstancias, merece la pena fijarse en las distintas traducciones de las cuatro novelas por las diferencias entre ellas. Sin ninguna duda, estas ocho versiones plantean un amplísimo abanico de estrategias, técnicas y maneras de ver y enfrentarse a la traducción.

\section{I. 'Woman Hollering Creek'}

La primera traducción de Woman Hollering Creek ( $W H C$ en lo sucesivo) fue realizada en I992 por Enrique de Hériz para la colección Tiempos Modernos de Ediciones B. De Hériz fue el responsable entre i987 y i99I del departamento de traducción de esta editorial. Cuando decidieron publicar en España a Sandra Cisneros, ésta ya llevaba varios años cosechando éxitos en Estados Unidos y se había convertido en la autora chicana más conocida y mediática, hasta el punto de ser famosa al margen de la corriente literaria chicana. Es mi impresión que, en cierta medida, se pensó que en España alcanzaría un éxito similar aun cuando el público no había oído hablar nunca de los chicanos, y mucho menos de su literatura.

Como consecuencia, las traducciones que se realizaron de $W H C$ y, como veremos en el siguiente apartado, de The House on Mango Street (THoMS en lo sucesivo) pueden ser consideradas domesticantes, porque se optó por neutralizar el idioma y utilizar un registro estándar y peninsular del español. De esta forma, a pesar de transmitir el sentido, a pesar de que se sabe qué está ocurriendo en cada momento, no se es capaz de contextualizarlo adecuadamente, dado que el tono de la novela, el habla de los personajes, no se corresponde con el contexto que habitan. Al perderse el tono, se pierde también gran parte de la carga ideológica del original, transmitida a través del lenguaje. Es decir, todas las implicaciones que conlleva la utilización de un inglés influenciado por y salpicado de palabras en español, una lengua que además está en una situación minorizada en Estados Unidos, se pierden por completo al utilizar el registro 
estándar en España, donde obviamente no supone ningún tipo de subversión. Lo mismo ocurre con la identidad cultural y lingüística de la autora y de los personajes de la obra, que pasa de ser muy visible en el original a prácticamente desaparecer en la traducción. Como la propia Cisneros afirma, a su padre, que nunca llegó a aprender inglés, estas versiones tan castellanas de sus novelas le resultarían tan alejadas de su México natal como el inglés utilizado en los originales.

Es curioso que ningún/a escritor/a chicano/a haya tenido un éxito arrollador en España cuando muchos sí lo han tenido en otros países europeos, esto es tanto más curioso si tenemos en cuenta que histórica, cultural y lingüísticamente están más cercanos a España que a cualquier otro país de Europa. Curiosamente, las traducciones publicadas en otras lenguas han sido más capaces de mantener esa identificación cultural y ese tono exótico que es tan complicado salvaguardar en español. Por lo tanto, $W H C$ pasa de ser un retrato cultural y social a ser una colección de relatos interesantes, bien escritos, pero que no añaden nada más. Para conseguir el mismo impacto del original necesitaríamos utilizar un registro de nuestro idioma que resultara tan chocante y subversivo para el lector español como lo es el original para la audiencia anglosajona. Sin embargo, hay muchos factores que influyen en el proceso traductor, factores relacionados con la influencia del poder en un nivel intercultural (es obvio que las jerarquías culturales impiden un acercamiento libre de estereotipos a una literatura minorizada), pero también intracultural. En primer lugar, no sabemos hasta qué punto la elección del registro del español fue decisión de de Hériz o de la editorial, que imaginó que conseguiría más ventas si la novela no causaba extrañeza a los lectores. En segundo lugar, cabría juzgar la traducción teniendo en cuenta el contexto teórico y laboral en el que fue realizada, ya que desde 1992 hasta ahora se ha avanzado y escrito mucho acerca de cómo traducir literatura híbrida y el tiempo ha hecho que muchos de estos escritores fueran estudiados y conocidos a fondo en nuestro país. Estas dos novelas fueron probablemente las primeras obras de una escritora chicana en traducirse y publicarse en España, por lo que la labor de de Hériz puede considerarse pionera en este campo.

La segunda versión de $W H C$ fue realizada en 1996 por Liliana Valenzuela para la editorial norteamericana Vintage. Su traducción demuestra, por una parte, que conoce a la perfección las características lingüísticas, culturales y sociales del contexto en el que se inscribe el texto original, puesto que aboga por un lenguaje híbrido tomando como punto de partida el español de México y «explicita la tensión entre una cultura y otra y la negativa a dejarse dominar por el inglés» (Vidal Claramonte, 2007: 98); y por la otra, que su situación es poderosa, ya que, al parecer, fue la propia Cisneros la que pidió que ella realizara una segunda versión. Esta posición de autoridad provoca «una traducción, cabría decir, antropofágica, en tanto no niega las influencias sino que las absorbe $y$ transforma añadiendo, y no olvidando, el elemento autóctono, multiplicando así los discursos, las voces del texto, y relativizando la visión tradicional de la traducción como representación mimética del original» (ibídem).

Paradójicamente, si bien en la versión de Enrique de Hériz la autora es absolutamente invisible para el público español, en la de Liliana Valenzuela puede llegar a quedar desaparecida tras la traductora, quien hace suyo el texto de forma que resulta más idiomático aún que el original. Las diferencias entre las dos traducciones de $W H C$ no están sólo presentes en el len-

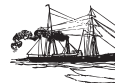


guaje, sino que «el propio libro como objeto ya deja claras las dos formas de ver la traducción» (ibídem: 95). Vidal Claramonte realiza un exce- lente análisis de cómo se tradujeron y adaptaron elementos que no forman parte de la historia en sí, sino que están relacionados con el formato².

\section{2. 'The House on Mango Street'}

Ediciones B decidió publicar THoMS, la primera y más conocida novela de Sandra Cisneros y la que la catapultó a la fama, al mismo tiempo que $W H C$, por lo que de Hériz realizó también esta traducción. $\mathrm{El}$ resultado es similar al analizado anteriormente: una versión que, si bien traslada el significado de las palabras con bastante exactitud, no transmite el vasto conjunto de implicaciones ideológicas y culturales que están presentes en el original. La segunda traducción de la novela fue publicada dos años después, en 1994, por Vintage (diez años más tarde, en 2004, Seix Barral la publicó en España) y realizada por Elena Poniatowska, escritora y periodista nacida en París, pero afincada en México desde su niñez. Poniatowska es una de las más destacadas figuras literarias de este país, ha publicado numerosas novelas y ganado un sinfín de premios, por lo que llama poderosamente la atención su traducción, realizada, al igual que la de Valenzuela, desde una situación de autoridad y con el beneplácito de la autora. THoMS es la obra de Cisneros en la que menos evidente resulta la hibridación en el lenguaje, posiblemente por ser la primera. La versión de Poniatowska mexicaniza el texto por completo al utilizar giros muy idiomáticos y propios del español de México para traducir expresiones que aparecen en inglés estándar en el original.

2 Por motivos de espacio no me es posible reflejar aquí el resultado de este estudio, por lo que remito a los lectores interesados a la obra de esta autora (Vidal Claramonte, 2007).
Al igual que ocurre con la otra novela, las diferencias entre ambas traducciones son evidentes desde el momento en que uno compara los dos libros. La portada original y la de la versión de Poniatowska son iguales, la imagen representa a tres mujeres con rasgos indígenas manipulando lo que parece ser una tela muy fina; en cambio, la portada de Ediciones B es un dibujo de una niña o adolescente de ojos grandes y larga melena clara. Obviamente, el contexto cultural al que remiten las portadas no es el mismo. En este caso, no hay mucho que decir del título: Una casa en Mango Street/La casa en Mango Street, ni de la dedicatoria, que en el original es bilingüe («A las Mujeres»/«To the Women») y marcada con la mayúscula, mientras que en las traducciones consta sólo en español y sin ninguna marca tipográfica. En la versión de Vintage aparece una breve biografía de la traductora, al igual que ocurría en la traducción de Valenzuela de WHC y, además, se añade una sección llamada "Agradecimientos» en la que Cisneros da las gracias a aquellos que la han ayudado a publicar esta traducción y deja constancia de la situación de autoridad de Poniatowska al afirmar que realizó este trabajo "como un favor, un regalo, una labor de amor» (Cisneros, 1994) y al resaltar su compromiso con la literatura chicana y su conocimiento del contexto que rodea a la producción del texto origen: «Por su continuo amor, solidaridad y apoyo hacia mí y otros escritores chicanos, le quedo eternamente agradecida» (ibídem). Al parecer, Cisneros no estaba satisfecha con las traducciones publicadas en España dos años antes y trató de que ambos libros fueran retraducidos por personas que tuvieran una conexión más cercana con el mundo del que tratan; la propia Poniatowska afirmó en una entrevista que a Cisneros su versión «le gusto más que una traducción que le habían hecho en España» 
(Pino-Ojeda, 2000: 56 ).

Además de estos elementos que no forman parte del texto literario, veamos dos ejemplos que muestran las diferencias a nivel lingüístico y cultural entre ambas traducciones. En la viñeta titulada «Louie, His Cousin \& His Other Cousin» encontramos a Marin, la chica portorriqueña que vive con sus tíos, cantando el comienzo de una canción anglosajona para jugar a la comba: «Apples, peaches, pumpkin, pa-ay. / You're in love and so am ah-ay.» (Cisneros, I99I [I984]: 24)3. Dado que la lengua materna del personaje es el español, el hecho de que cante una canción infantil en inglés no es casual, sino que es un signo de hibridación social y cultural. Poniatowska opta por no traducir la letra y mantenerla igual en su versión, mientras que de Hériz se inventa dos frases ( Frutas, flores y un vaivén. / Tú me quieres y yo también.») cuyo significado va en la misma línea que la cantinela inglesa, pero que no remiten a ningún contexto, ni híbrido, ni mexicano, ni español porque no son reconocibles por el lector. Una situación similar se da en la viñeta «Hips» («Caderas» en las dos traducciones españolas). Las niñas están jugando a la comba e inventándose canciones, pero Nenny, que es la más pequeña, recurre a canciones populares porque no es capaz de discurrir una letra nueva. Una vez más, resulta un signo claro de adaptación cultural que canten en inglés y, sobre todo, que las canciones que escoge Nenny pertenezcan al sustrato popular estadounidense, en lugar de al mexicano:

My mother and your mother were washing clothes.

My mother punched your mother right in the nose

What color blood came out? [...]

3 La letra completa puede consultarse en la red: http://etymo.xanga.com/645156273/pie/.
Engine, engine number nine, running down Chicano line.

If the train runs off the track do you want your money back?

Do you want you MONEY back?

Yes, no, maybe so. Yes, no, maybe so... (Cisneros, I99I [I984]: 52).

De Hériz opta por dos canciones populares para niños pertenecientes al sustrato cultural de España, por lo que, si bien el significado se transmite, la remisión cultural no es correcta, de hecho, no tiene sentido, ya que ¿por qué iba a cantar una canción típica española una niña de padres mexicanos, crecida en Estados Unidos?:

El cocherito leré me dijo anoche leré que si quería leré montar en coche leré. [...]

Al pasar la barca me dijo el barquero

las niñas bonitas no pagan dinero.

Yo no soy bonita ni lo quiero ser... (Cisneros, I992b: 78).

Poniatowska utiliza dos tonadillas propias del cancionero infantil mexicano (la segunda es también muy conocida en España, aunque con distinto final):

\section{Patito, patito}

color de café,

si usté no me quiere

pos luego por qué. [...]

Dos y dos son cuatro, cuatro y dos son seis, seis y dos son ocho y ocho, dieciséis, y ocho veinticuatro y ocho treinta y dos, ánimas benditas que se me murió. (Cisneros, 1994: 53).

De esta manera, remite al lector a la cultura popular mexicana que, a pesar de ser más cerca-

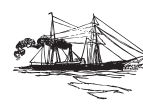

89 
na al contexto de origen que la española, no es tampoco la identidad cultural a la que se refiere el texto de Cisneros. Si en el ejemplo anterior se 90 ha optado por dejar la canción sin traducir, en este capítulo se podría haber tomado la misma decisión. El hecho de que las niñas canten tonadillas anglosajonas señala su adaptación al mundo norteamericano, puesto que este tipo de canciones se aprenden en el colegio (un entorno marcado por el inglés) y jugando en la calle con otros niños (todos ellos colegiales y, por lo tanto, hablantes de inglés). Los elementos populares como éste tienen unas connotaciones culturales muy fuertes, porque son muy específicos; si Cisneros hubiera querido remitir al mundo mexicano, hubiera insertado las canciones en español en el texto inglés, de la misma manera que a veces inserta los apodos y nombres cariñosos («abuelito», «mamacita»). Por lo tanto, dado que no conllevan ningún significado en sí mismas, posiblemente la traducción más apropiada sería dejarlas en inglés, quizá añadiendo una nota que explicara que son canciones populares anglosajonas.

En conclusión, a pesar de que ambas versiones muestran un esfuerzo por parte de los traductores, aunque el sentido se mantiene y el tono literario también, la obra está tan cargada de remisiones culturales que ni de Hériz ni Poniatowska logran transmitir del todo la identidad híbrida patente en el original, lo cual, sobre todo nos demuestra que la tarea de traducir a estas autoras puede llegar a ser fascinante y frustrante a partes iguales.

\section{3. 'How the Garcia Girls Lost Their Accents'}

La primera traducción de esta novela de Julia Álvarez fue, al igual que la de las dos obras ya analizadas, publicada en la colección Tiempos Modernos de Ediciones B. En esta versión, realizada por Jordi Gubern en el año I994 (el

original fue publicado en r99I), si bien se mantiene el bilingüismo, se utiliza el español peninsular para dar voz a unos personajes que son dominicanos, lo que hace que Martín Ruano se pregunte si en esta estrategia «cabe ver a la antigua potencia colonial en funcionamiento» (2003: 25I).

Efectivamente, Álvarez no se mostró precisamente satisfecha con esta traducción en la que, por ejemplo, se emplea el pronombre «vosotros» para la segunda persona del plural cuando no se usa en ningún país de America Latina. Sin embargo, el traductor sí muestra cierta preocupación por el contexto lingüístico, ya que desde la primera página señala el cambio de código del original al incluir una nota en la que dice que indicará con cursiva todas las palabras que figuran en español en el texto origen. También trata, en algunos momentos, de mantener el juego entre lenguas, pero sin una estrategia sistemática, puesto que opta por dejar ciertos elementos en inglés, pero elimina otros que a menudo son más importantes. Por ejemplo, al comienzo del libro Yolanda se reencuentra con Carmencita y ésta utiliza una expresión en inglés («Older, not wiser»), se nos explica que esto se debe a que estuvo dos o tres años en un internado en Estados Unidos; Gubern opta por dejarla en inglés para mantener el texto bilingüe y que la explicación siga teniendo sentido y traduce la expresión en una nota a pie de página. En cambio, cuando Yolanda y John están escuchando la radio y suena una canción de los Beatles, All you need is love: «'All you need is love,' the radio wailed, as if it were hungry. [...] 'Love', the song snarled, starved. 'Love... love...'» (Álvarez, I991: 70-I); curiosamente opta por traducir la referencia cultural cuando es bastante obvia, ya que la canción es muy conocida; de hecho, es al traducirla cuando pierde claridad porque no se relaciona de forma 
inmediata con la original: «-Todo lo que necesitas es amor -gimió la radio, como si estuviera hambrienta.[...]-Amor-rezongaba la canción, ciertamente famélica-. Amor... amor...» (Álvarez, 1994: 77).

La segunda traducción de la novela fue realizada por Mercedes Guhl y revisada por Ruth Herrera en 2007 para la misma editorial que había publicado el texto original. Al parecer, Álvarez quedó mucho más contenta con esta nueva versión, porque Guhl es conocedora de la voz caribeña y, por lo tanto, respeta los modismos y giros idiomáticos dominicanos sin que eso afecte a la comprensión general del texto para otros hispanohablantes. En efecto, en esta versión se utiliza un español más cercano a la variante dominicana tanto en los términos («carros», «guagua»), como en el uso del pronombre «ustedes» para la segunda persona del plural («Ustedes cuatro se pierden por allá» [p. I8], «Caramba con ustedes dos» [79]). En cambio, no se marca de ninguna manera la presencia de vocablos españoles en el texto inglés y resulta curioso comprobar que tampoco se sigue una estrategia sistemática para las referencias culturales y lingüísticas. De hecho, si observamos los ejemplos mencionados, Guhl opta por traducir las palabras de Carmencita al español, pero mantiene en inglés el título y la letra de la canción de los Beatles.

$\mathrm{Si}$ analizamos otras diferencias que presentan ambos libros, vemos que, una vez más, las portadas cambian. En la original, la imagen muestra las piernas de una chica que lleva un vestido o falda corta y calza unos zapatos rojos. La portada de la versión de Guhl es igual y, en cambio, en la de Gubern vemos las piernas de cuatro chicas, todas ellas calzadas de la misma forma. Sin embargo, es cierto que en este caso las remisiones que provocan las diversas imágenes no son $\tan$ diferentes como en las novelas de Cisneros. Lo segundo que llama la atención es el título: De cómo las chicas García perdieron su acento (Gubern) y De cómo las muchachas García perdieron el acento (Guhl). Ya que «chicas» es un vocablo que rara vez se emplea en el español caribeño, sería mejor la adaptación de Guhl; sin embargo, es difícil calibrar hasta qué punto es una elección del traductor, ya que a menudo son las editoriales las que escogen el título basándose, no sólo en cuestiones lingüísticas o culturales, sino también en cuestiones de marketing. E1 tercer elemento en el que encontramos ciertos detalles curiosos es el árbol genealógico que Álvarez introduce al comienzo de la novela para aclarar las relaciones familiares. Por ejemplo, donde el original dice "Carlos m. Laura», siendo la m. la abreviatura de married, Gubern traduce "Carlos casado con Laura», pero Guhl mantiene "Carlos m. Laura», a pesar de que en español esa abreviatura no tiene sentido en ese contexto. Por otra parte, hay un error incomprensible en la traducción de great-greatgrandfather como bisabuelo y también Gubern comete un error inexplicable al traducir «The hair-and-nails cousins» por «El resto de los primos».

Para terminar, observaremos una característica fundamental a lo largo de la novela que demuestra que ninguno de los dos traductores ha seguido una estrategia sistemática respecto a los conflictos lingüísticos. En el original, Álvarez recalca en varias ocasiones que la madre de las niñas, Laura, habla inglés pero no de forma totalmente correcta, y éste es un elemento importante porque marca la distancia con sus hijas. Es decir, las niñas hablan un inglés perfecto y, por lo tanto, su adaptación al contexto norteamericano es mayor que la de su madre; de la misma manera, las niñas no hablan un español fluido, mientras que su madre sí lo hace. La forma en que los personajes utilizan una 
lengua es de gran significancia en este tipo de literatura porque es una señal de su identidad, por lo que es importante que en la traducción también quede claro. Veamos tres momentos de la novela en los que se hace patente el nivel de inglés de la madre y las consiguientes traducciones al español. La primera situación se da cuando Laura va a un recital de poesía a escuchar a Yolanda y trata de recitar unos versos de un poema de Poe que no consigue recordar bien:

Many many years ago, something... something, In a... something by the sea...

A princess there lived whom you may remember

By the name of Annabel Lee... (Álvarez, I99I: 50)

Gubern opta por traducirlo al español, y no sería una decisión desacertada si no fuera porque el hecho de que no recuerde bien el poema probablemente se debe en parte a que está en inglés. Guhl, en cambio, mantiene el texto igual que aparece en el original y lo traduce en una nota a pie de página en la que, además, explica a qué poema se refieren.

La segunda situación se da cuando la madre cita de forma errónea un refrán inglés: «Sticks and stones don't break bones»(p. I35). Guhl lo adapta utilizando y cambiando un dicho español: «A pedradas necias, oídos sordos» ( $p$. I67), una solución buena si no fuera porque no remite al contexto lingüístico del original. Por el contrario, Gubern mantiene la expresión en inglés y escribe una nota a pie de página explicando lo que ocurre: "Palos y piedras no rompen huesos.' Laura cita erróneamente un proverbio inglés que dice precisamente todo lo contrario: 'Palos y piedras romperán mis huesos, pero los insultos (o 'las palabras', según el caso) no me herirán.'» (Álvarez, I994: I39). E1 tercer ejemplo tiene lugar cuando Yolanda está tratando de escribir un discurso para una fiesta en la escuela y su madre le pone como ejemplo el famoso discurso que Lincoln pronunció en Gettysburg y al intentar citar la primera frase se equivoca y en lugar de Four score and seven years ago, dice «Four score and once upon a time ago» (p. I42). Gubern elimina por completo la referencia y simplemente dice: «le salió uno de los discursos más bellos de la historia» (Álvarez, I994: I45), mientras que Guhl mantiene la frase original y explica la situación en una nota a pie de página:

Como sucede con tantas otras cosas que cita, Laura García no acierta con las primeras palabras del discurso que Abraham Lincoln pronunció en Gettysburg, donde se libró una de las grandes batallas de la Guerra de Secesión, que dicen: Four score and seven years ago [Hace ochenta y siete años], refiriéndose al momento de la independencia de Estados Unidos, y las mezcla con el comienzo tradicional de los cuentos de hadas Once upon a time [érase una vez] para terminar con algo que en español podría traducirse como «Hace ochenta años, había una vez...», y que no tendría mucho sentido en boca de Lincoln» (Álvarez, 2007: I75).

Ninguno de los dos traductores es sistemático en la forma de tratar este problema, como tampoco lo son en sus decisiones respecto a los conflictos lingüísticos y culturales que plantea la traducción de la novela. Por lo tanto, si bien ambas versiones ofrecen buenas soluciones, el nivel de calidad no es homogéneo a lo largo de ninguna de las dos.

\section{4. 'How Tia Lola Came To Visit Stay'}

El caso de esta novela, escrita para niños, es ligeramente diferente dado que las dos traducciones que existen fueron hechas en América. La primera la realizó Carolina Sanín Paz en 200I (el mismo año en que se publicó el texto 
original) para Random House, la misma editorial que publicó el texto original. Sanín Paz es colombiana por lo que no le es extraño el español caribeño que utilizan los personajes y, de hecho, lo mantiene en la traducción. La segunda versión la hizo Liliana Valenzuela en el 2004 también para Random House. Parece, pues, que la autora o los editores no quedaron demasiado satisfechos con el trabajo de Sanín Paz $y$ decidieron encargar a Valenzuela una nueva traducción en la que es posible que hubiera cierto grado de colaboración con Álvarez, como demuestra el hecho de que la sección final, en la que la autora explica la variedad de español que hablan los personajes de la novela, varía ligeramente en esta versión y aparece firmada por las dos, lo cual incita a pensar que los cambios fueron decididos conjuntamente. Una vez más, se hace patente el poder de Valenzuela como figura de autoridad reconocida en este campo.

$\mathrm{Al}$ igual que en los casos anteriores, la portada de la segunda versión es igual que la del original (un dibujo de un paisaje nevado con una casa a la que se dirige una mujer con el pelo recogido en un moño adornado con una flor, vestida con una falda de flores de alegres colores, que lleva un bolso en una mano y un loro en la otra), mientras que la de la primera traducción es diferente (el dibujo muestra varias maletas y a una mujer de rasgos caribeños, peinada con un moño adornado con una flor, vestida con un vestido de flores de colores y unos zapatos de tacón alto, que coge en brazos a una niña mientras un niño las mira con expresión de descontento; ambos niños tienen también rasgos faciales típicos de los países del Caribe). Sin embargo, aunque las portadas cambien, la referencia cultural no lo hace y, además, ambas traducciones tienen el mismo título.

La variedad del español es similar en ambas versiones («Pero, niños, por favor: no le pre- gunten sobre eso, ¿okay?» [Álvarez, 20orb: I3]; "Hagan como que estamos en el restaurante chino y compartimos todos los platos» [Álvarez, 2004: 4]) y las dos utilizan palabras propias del español de Sudamérica, si bien es cierto que Sanín Paz tiende a estandarizar más que Valenzuela, quien sistemáticamente emplea esta variedad del lenguaje. Por ejemplo, donde Álvarez pone «bus» (p. 2), Sanín Paz utiliza «autobús» (p. Io), mientras que Valenzuela escribe «guagua» (p. 2). Lo mismo ocurre con chips/«patatas»/«papitas», con peanut/«cacahuete»/«maní» o con lunchbox/ «fiambrera»/«lonchera». Tal y como ocurría en las novelas que hemos analizado antes, al emplear un español más estándar se transmite el sentido, pero se pierde el contexto. Dado que el personaje principal de la novela, Tía Lola, no habla inglés, mientras que los niños apenas saben chapurrear un par de frases en español, la tensión lingüística entre ellos es constante. De hecho, la historia acaba siendo un auténtico canto al bilingüismo, ya que Tía Lola consigue aprender algo de inglés y los niños acaban mejorando mucho su español. El original presenta muchísimas palabras y frases en este idioma que, a menudo, aparecen luego traducidas al inglés para facilitar la comprensión del texto. Al ser un cuento para niños, hay cierta intención pedagógica en esta técnica, como explica Álvarez al final de la obra: «As for those of you who might not know any Spanish at all, I've tried always, siempre, to translate each phrase or word right after the Spanish, so that in reading about Tía Lola, you (like Miguel and Juanita) might learn a little bit of Spanish, un poquito de español, from her» (Álvarez, 200I: 146).

Sanín Paz opta por marcar en cursiva todas aquellas palabras y frases que aparecen en español en el original y así nos lo explica en una nota en la primera página. Sin embargo, a pesar 
de hacer patente que el texto de origen es bilingüe, su traducción no lo es, ya que hay poquísimas palabras en inglés. En cambio, Valenzuela 94 no marca de ninguna manera el hecho de que la autora emplee el español en el original, pero su texto sí incluye frases en inglés, especialmente en aquellos diálogos en los que se plantea un conflicto lingüístico. De alguna manera, cuando puede, trata de compensar el hecho de que la lengua de la traducción es la que funciona como subversiva en el texto origen, por lo que si queremos causar el mismo efecto en los lectores hispanos, tendremos que recurrir a situaciones en las que podamos jugar con el inglés. Veamos un ejemplo:

Every opportunity they have, Miguel and Juanita give their aunt an English lesson.

On the walk to town, Miguel stops at the sign beside the covered bridge. «Load limit: one ton.»

«Load-limit-one-ton,» Tía Lola repeats. [...]

Then the traffic signs. «One way,» he calls off. «Caution.»

The crossing guard holds up her stop sign to the traffic. «Have a nice day,» she says when they have crossed safely to the other side.

«One-way-caution-you're-welcomethanks-for-asking,» Tía Lola chatters on. That is the problem with Tía Lola's English. Whenever she begins speaking it, she speaks all of it, all together. (Álvarez, 20or: 62-63)

En la primera versión se opta por traducir todo al español, aunque explicitando que en realidad están hablando inglés. De esta forma, la escena resulta graciosa para los lectores hispanos, aunque en cierta medida se pierda el juego lingǘstico:

Siempre que pueden, Miguel y Juanita, le dan a su tía lecciones de inglés.

De camino al pueblo, Miguel se detiene frente a la señal que hay junto al puente cubierto.

—Límite: una tonelada.

—Límite: una tonelada — repite Tía Lola. $[\ldots]$

Luego las señales de tráfico.

- Calle de sentido único - anuncia Miguel一. Cuidado.

Una agente de tráfico, en el cruce de peatones, muestra su señal de «stop» a los coches para que se detengan.

-Que tengan buen día - dice cuando Miguel y Tía Lola han llegado a salvo al otro lado.

-Sentido-único-cuidado-de-nada-gracias-por-preguntar - parlotea Tía Lola.

Ése es el problema con su inglés: cuando empieza a hablar, le sale todo, todo a la vez. (Álvarez, 200rb: 56-57).

Valenzuela traduce la escena manteniendo las expresiones inglesas, de esta manera la escena podría perder gracia para un lector hispano que no hable inglés, pero aprovecha la situación para compensar otras en las que el bilingüismo se pierde y además mantiene la intención pedagógica de Álvarez aunque en el sentido contrario:

Ahora, en cada oportunidad que se les presenta, Miguel y Juanita le dan a su tía lecciones de inglés.

En el camino al pueblo, Miguel se detiene frente a la señal que hay junto al puente techado que dice "Límite de carga: una tonelada».

-Load limit: one ton -le lee en inglés Miguel a su tía.

[...] Load-limit-one-ton - repite tía Lola.

Luego, las señales de tráfico: -One Way quiere decir Una Vía —explica Miguel一, y Caution es Cuidado. 
La mujer policía sostiene su señal de pare en el cruce de peatones.

- Have a nice day - les desea que tengan un buen día, cuando han llegado a salvo al otro lado.

-One-way-caution-you're-welcomethanks-for-asking - parlotea tía Lola. Ese es el problema con la forma que tiene de hablar inglés: cuando comienza, lo habla todo pegado y de un tirón (Álvarez, 2004: 57-58).

Algo parecido ocurre cuando la madre de los niños usa refranes ingleses como «to have a green thumb» o «to rain cats and dogs» y tía Lola los entiende de forma literal. Sanín Paz los traduce literalmente al español («Becky tiene el pulgar verde», «Están lloviendo gatos y perros»), mientras que Valenzuela los mantiene en inglés $y$, de nuevo, aprovecha para sumergir al lector en ese mundo bilingüe. Obviamente, estas decisiones provocan que el receptor tenga que implicarse más en la lectura, ya que la comprensión total de la obra requiere de su participación, lo cual también ocurre en el texto original; esta dimensión pedagógica, en cambio, se echa de menos en la versión de Sanín Paz.

\section{EL PULSO AUTOR-TRADUCTOR-EDITOR}

Es obvio que estas nuevas literaturas mestizas cuestionan el concepto tradicional de traducción; sin duda, tenemos una responsabilidad especial cuando nos enfrentamos a textos marcados ideológicamente, como los analizados aquí. Nuestra labor va más allá del trasvase lingüístico o incluso de la transmisión del sentido, ya que todos los elementos que componen estos libros tienen un objetivo ideológico que debe hacerse patente. Desde la imagen de la portada hasta el lenguaje utilizado, desde la biografía de la autora hasta la más mínima referencia cultu- ral. Lograr la comprensión total es tan imposible como conseguir la traducción perfecta, pero nuestro objetivo estará más cerca si nos implicamos y tenemos en cuenta que la traducción de estas literaturas sólo puede hacerse desde un espacio de comprensión y diálogo en el que nos contagiemos del espíritu híbrido del original. Sin embargo, no siempre es realista presuponer una situación en la que el traductor realiza su trabajo en las condiciones idóneas.

Ya hemos visto que las traducciones de estas obras no siempre mantienen el tono, las implicaciones ideológicas o el sabor del original y, por lo tanto, suelen ser susceptibles de crítica por los teóricos o académicos especializados. Si bien es cierto que los análisis y comparaciones contribuyen a la expansión de nuestra disciplina y nos proporcionan una visión crítica que es absolutamente necesaria para avanzar y perfeccionar nuevas técnicas de traducción, a menudo se echa en falta en ellas la consideración de otros mecanismos de poder que quizás no son tan visibles, pero que están ahí y condicionan el trabajo del traductor. Me refiero a las jerarquías y relaciones asimétricas que operan dentro del propio mundo editorial y que condicionan todo el proceso de publicación de una traducción.

Al margen de asuntos más teóricos como pueden ser las divergencias en ideologías, identidades, entorno social y cultural, etc., al fin y al cabo, la traducción es un trabajo y, como tal, a menudo quien lo realiza no sólo ha de tener en cuenta las consideraciones artísticas, sino también el hecho de que vive y come de él. Como es obvio, no todos pueden darse siempre el gusto de escoger, "así las cosas, el traductor no se lo piensa dos veces: acepta lo que le cae y ruega a San Jerónimo que no falte» (De Prada et al., I996: 90). De esta forma, acepta un mecenazgo y esto implica que "rewriters work within the parameters set by their patrons and that they 
should be willing and able to legitimize both the status and the power of those patrons» (Lefevere, I992: I8). En este caso, el editor es el 96 emisor cultural que tiene el poder, él decide qué y cómo se traduce. Es evidente que la cultura de destino sólo tiene acceso a una selección de obras procedentes de la de origen, porque no se puede traducir todo, pero cabe preguntarse cómo se realiza esa selección. ¿En qué se basa una editorial para escoger ciertas obras y rechazar otras? ¿En la calidad o en la capacidad de ventas? Es muy probable que escoja aquellas obras que mejor se adaptan a las expectativas del público receptor y que, por lo tanto, continúan alimentando la imagen parcial que éste tiene de la cultura origen. Así, la imagen que formamos de una comunidad a través de las reescrituras a las que tenemos acceso pasa por un doble filtro: el del mecenas y el del traductor. Como afirma Tymoczko (2000: 24), la traducción literaria es parcial por dos razones; la primera es que sólo se puede traducir "part of a corpus of source texts and part of the meanings readable in any one of these texts»; la segunda que los traductores, y cabría añadir que los editores también, son partidistas y se implican ideológicamente en sus elecciones. Aparte de las posibles razones ideológicas, no hay que olvidar que las razones económicas inevitablemente influyen, puesto que, al fin y al cabo, las editoriales son negocios y tratan de obtener los máximos beneficios posibles. Por ello, se realizan traducciones que se adaptan a las perspectivas del público receptor y que son lecturas fáciles; es decir, si una obra utiliza un lenguaje híbrido, resulta más simple traducirlo a inglés, español o francés estándar que mantener el juego entre lenguas y explicarle el contexto al lector o confiar en que será capaz de averiguarlo por su cuenta.

Dada la particular naturaleza de su trabajo, el traductor está sometido a todo tipo de presio-

nes, por una parte están aquellas que tienen que ver con la ideología y las relaciones de poder entre las dos lenguas. Pero además, el editor representa el papel del mecenas del que habla Lefevere y, por lo tanto, impone una serie de constraints temporales, económicas, etc. que se suman a las que el propio traductor se impone a sí mismo y que pueden limitar su trabajo en términos de calidad. Silvia Querini, editora de Ediciones B en la época en que se publicaron las traducciones de Enrique de Hériz y Jordi Gubern que hemos analizado, afirma que no admite «que se justifique una traducción mediocre poniendo como excusa la falta de tiempo o una remuneración no acorde con el esfuerzo» (Querini, I996: 92), ya que el traductor puede siempre decir que no puede o no quiere realizar el trabajo. Sin embargo, es evidente que uno no puede esperar la perfección de una traducción «hecha con el agua al cuello, con unas tarifas pésimas» (De Prada et al., I996: 90); las prisas no suelen conjugar bien con la necesidad de documentación que a menudo evidencia un mal trabajo. Así, tener poco tiempo o cobrar unos honorarios muy bajos puede influir negativamente en la calidad de la labor. De la misma forma, tener una posición precaria en el mundo de la traducción puede ocasionar que no se sea capaz de negociar con el editor cierta libertad a la hora de decidir cómo debe ser la traducción o de justificar las decisiones tomadas, una libertad que, como hemos visto, sí tienen ciertos traductores que alcanzan una situación de poder y que son reconocidos como figuras de autoridad. Una posición precaria también puede llevar a la auto-censura, a realizar una versión más neutra o naturalizada por temor a que el corrector o el editor no la consideren adecuada. Es decir, cuando realizamos una crítica de una traducción es importante tener en cuenta que, en ocasiones, es el editor 
quien impone sus opiniones y que si el traductor no las acata, es despedido o corregido, ya que en este pulso a tres bandas suele participar también una cuarta parte cuya labor es fundamental que esté bien conjugada con la nuestra: los correctores, quienes «bolígrafo rojo en ristre, van a la busca y captura del gazapo en ocasiones más imaginario que real» (ibídem), modificando un texto que luego aparecerá firmado por el traductor. ¿Qué ocurre en el caso de la literatura híbrida? ¿Deja el corrector pasar las expresiones en inglés o en variedades del español propias de Sudamérica? Si no se permite la participación del traductor en el proceso de corrección, estamos dejando el texto en manos de alguien que no tiene por qué conocer en absoluto el contexto de origen. ¿Para qué pedir al traductor que se documente si luego se le da la última palabra a alguien que quizá desconoce por completo las circunstancias en las que se ha escrito la obra? «A la hora de consultar, el traductor no existe» (ib.: 9I), por lo que éste ve el resultado final de su trabajo cuando ya ha sido publicado con su nombre. Y cuando decimos resultado final, no nos referimos simplemente al texto, sino también a otros elementos que, como hemos visto, son fundamentales en el proceso de recepción de una obra literaria y sobre los que el traductor nada puede decir.

\section{CONCLUSIONES}

En conclusión, ya sabemos que puede haber muchas estrategias de traducción y que cada una revela unas motivaciones, una ideología y una actitud respecto al texto, pero no deberíamos olvidar que éstas no siempre corresponden al traductor, sino al agente que tiene el poder en el proceso. Como hemos visto, en algunos casos sí es el traductor el que ostenta esa posición de autoridad, pero en muchos otros su trabajo está a merced de las preferencias editoriales.

E1 primer paso para asegurar una buena traducción es que haya comunicación y colaboración entre los agentes implicados en el proceso de publicación de una obra literaria: autor (siempre que sea posible), traductor, corrector y editor. Esta aspiración puede parecer utópica, pero es evidente que la relación por la que abogamos ha existido en algunos de los casos que se han examinado antes, no es casualidad que concretamente sea en aquellos que han salido mejor parados del análisis. Otro buen ejemplo de las ventajas que esta colaboración puede conllevar lo tenemos en la excelente traducción al español que Liliana Valenzuela realizó de Caramelo de Sandra Cisneros, en la que tanto la Nota del editor como la Nota de la Traductora, algo muy poco común en ediciones no académicas, evidencian la actitud del editor respecto al proceso traductor, así como «his open support for this critical contribution accompanying the published translation» (Sales, 2006). Es fundamental potenciar este tipo de actitudes, porque el traductor no puede enfrentarse solo a su labor, ya que no sólo de él depende el proceso de publicación de una obra. El editor y el corrector completan un triángulo que, por desgracia, no suele ser equilátero.

RECIBIDO EN JUNIO DE 2009 ACEPTADO EN OCTUBRE DE 2009 VERSIÓN FINAL DE ENERO DE 2010

\section{REFERENCIAS BIBLIOGRÁFICAS}

Álvarez, J. (1991). How the García Girls Lost Their Accents, New York: Plume.

- (1994). De cómo las chicas García perdieron su acento, Barcelona: Ediciones B. Trad. J. Gubern.

- (200I). How Tía Lola came to visit stay, New York: Yearling. 
- (20orb). Cuando Tía Lola vino te visita a quedarse, Barcelona: RBA. Trad. C. Sanín Paz.

- (2004). Cuando Tía Lola vino visita a quedarse, New York: Yearling.

98 - (2007). De cómo las muchachas Garcia perdieron el acento, Madrid: Punto de lectura. Trad. M. Guhl.

Bassnett, S. y H. Trivedi (eds.) (I999). Post-colonial Translation. Theory and Practice, London and New York: Routledge.

Cisneros, S. (1991 [1984]). The House on Mango Street, New York: Vintage Books.

- (I99I). Woman Hollering Creek and other stories, New York: Vintage Books.

- (1992). Érase un hombre, érase una mujer, Barcelona: Ediciones B. Trad. E. de Hériz.

- (1992b). Una casa en Mango Street, Barcelona: Ediciones B. Trad. E. de Hériz.

- (1994). La casa en Mango Street, New York: Vintage Español. Trad. E. Poniatowska.

- (I996). El arroyo de la Llorona y otros cuentos, New York: Vintage Español. Trad. L. Valenzuela.

De Prada, J. M. et al. (1996). «De nada». Vasos Comunicantes, 7, pp. 90-9I.

Godayol, P. (1999). «Escriure (a) la frontera: autores bilingües, traductores culturals». Quaderns, 3, pp. 29-37.

Lefevere, A. (1992). Translation, Rewriting and the Manipulation of Literary Fame, London: Routledge.

Martín Ruano, R. (2003). «Una (re)visión de la mirada sobre lo otro: el discurso crítico de los estudios de traducción y sus límites» en M. C. A. Vidal Claramonte et al. (eds.) Panorama actual de la investigación en traducción e interpretación, Granada: Atrio, pp. 24I-55.

Pino-Ojeda, W. (200o). Sobre castas y puentes: conversaciones con Elena Poniatowska, Rosario Ferré y Diamela Eltit, Santiago de Chile: Editorial Cuarto Propio.

Querini, S. (I996). «Gracias». Vasos Comunicantes, 7, pp. 9I-92.

Sales, D. (2006). «Documentation as Ethics in Postcolonial Translation»<http://accurapid.com/ journal $/ 35$ documentation.htm>

Tymoczko, M. (2000). "Translation and Political Engagement: Activism, Social Change and the Role Of Translation in Geopolitical Shifts». The Translator, 6 (I), pp. 23-47.

Valenzuela, L. (2003). «Nota a la traducción: el revés del bordado» en S. Cisneros. Caramelo, Barcelona: Seix Barral, pp. 539-44.

Vidal Claramonte, M. C. A. (2007). Traducir entre culturas: diferencias, poderes, identidades, Berna: Peter Lang. 